\title{
Correspondence
}

\section{Gastric emptying in term and preterm infants}

\section{Sir,}

Contrary to clinical impression the view now held is that the rates of gastric emptying in term and preterm infants are similar. Cited in support of this view is a paper published in the Archives ( $Y u, 1975)$. Yu stated that 'similar rates of gastric emptying were obtained in term, preterm, and SFD infants'.

This conclusion was erroneous. Gastric emptying is dependent on volume (Hunt and MacDonald, 1954), so for comparisons between groups of babies the volume should be kept constant. In this study the volume given was $7 \mathrm{ml} / \mathrm{kg}$, but it should be noted that the mean weight difference between the term and preterm infants was more than $1 \mathrm{~kg}$. Even though the percentage of the test meal recovered after 30 minutes was similar in term and preterm infants, it should be apparent that the number of $\mathrm{cc}$ evacuated in $\mathbf{3 0}$ minutes was more in term infants. The evidence presented in this study supports the clinical impression that gastric emptying is more rapid in term infants, but no firm conclusion can be drawn because of the differences in the volumes given.

I. BLumenthaL 8 Parva Springs, Tintern, $\mathrm{Nr}$ Chepstow.

\section{References}

Hunt, J. N., and MacDonald, I. (1954). Influence of volume on gastric emptying. Journal of Physiology, 126, 459-474.

Yu, V. Y. H. (1975). Effect of body position on gastric emptying in the neonate Archives of Disease in Childhood, 50, 500-504. 